\title{
MODELO ACESSÍVEL DE BALANÇO PARA CRIANÇAS COM NECESSIDADES ESPECIAIS: CONTRIBUIÇÕES PARA O DESIGN UNIVERSAL
}

\section{ACCESSIBLE BALANCE MODEL FOR CHILDREN WITH SPECIAL NEEDS: CONTRIBUTIONS TO UNIVERSAL DESIGN}

\author{
Bethânya Graick Carizio Me. ${ }^{l}$ \\ Sheila Moraes Raszl Esp. ${ }^{2}$ \\ Eduardo Augusto Souza Fernandes ${ }^{3}$ \\ Luis Carlos Paschoarelli Dr. ${ }^{4}$ \\ Sérgio Tosi Rodrigues Dr.5 \\ (1) Universidade Estadual Paulista "Júlio de Mesquita Filho" \\ bethanya.carizio@yahoo.com.br \\ (2) Centro Universitário UNIFAFIBE \\ sheilaraszl@yahoo.com.br \\ (3) Centro Universitário UNIFAFIBE \\ eduardo.asfernandes@hotmail.com \\ (4) Universidade Estadual Paulista "Júlio de Mesquita Filho" \\ paschoarelli@faac.unesp.br \\ (5) Universidade Estadual Paulista "Júlio de Mesquita Filho" \\ srodrigu@fc.unesp.br
}

Palavras-chave: Balanço Acessível, Design Universal, Parque Infantil

\begin{abstract}
Resumo: De acordo com a Declaração Universal dos Direitos da Criança e do Estatuto da Criança e do Adolescente, é necessária a elaboração de parques infantis acessíveis que permitam a integração de crianças, minimizando as possíveis diferenças. Pesquisas revelam que a maioria dos brinquedos de parques infantis não possui design que favoreça a inclusão de crianças com necessidades especiais. É neste contexto que o presente artigo objetiva apresentar um modelo de balanço acessível, projetado à luz dos princípios do Design Universal, para um parque infantil da Associação de Pais e Amigos dos Excepcionais - APAE- de uma cidade no interior paulista, destinado a crianças de quatro a 12 anos, acometidas por deficiências e síndromes múltiplas.
\end{abstract}

Key-words: Accessible Balance, Universal Design, Playground

Abstract: According to the Universal Declaration of the Children Rights and the Brazilian Statute of the Child and Adolescent, it is necessary to create accessible playgrounds that allow the integration of children, minimizing possible differences. Previous studies show that most playground toys do not have a design that favors the inclusion of children with special needs.It is in this context that this article aims to present an accessible balance model, designed in the light of the concepts of Universal Design, in a park for children of the Association of Parents and Friends of the Exceptional - APAE- of a city in the São Paulo State, to be used by children aged four to 12 years, suffering from multiple disabilities and syndromes. 


\section{$16^{\circ}$ \\ ERGODESIGN USIHC CINAHPA}

\section{Introdução}

O ser humano tem o direito de desfrutar das condições imprescindíveis para o desenvolvimento de seus talentos e vontades, sem ser exposto a qualquer tipo de discriminação (Cartilha-Censo, 2010, p.6). De acordo com o censo realizado em 2010 pelo IBGE (Instituto Brasileiro de Geografia e Estatística), 45,6 milhões de brasileiros têm algum tipo de deficiência, abarcando $23,9 \%$ da população. A deficiência motora é a segunda no ranking, acometendo $7 \%$ da população do Brasil e deficiências mental ou intelectual 1,4\%. Do total de deficientes no Brasil, 7,53\% são crianças e adolescentes de zero a 14 anos.

Uma vez que toda criança tem direito ao lazer e ao divertimento, as prefeituras das cidades têm se preocupado cada vez mais em oferecer ambientes de lazer para as crianças, mas estes ambientes estão preparados para receber um público considerado "diferente"? Os parques infantis têm se preocupado com a acessibilidade de seus espaços e brinquedos? Será que crianças com necessidades especiais devem se confinar em espaços de instituições de ensino especializadas para poder desfrutar do direito de se divertir?

Devido aos avanços nos processos produtivos, pesquisas em ergonomia e à criação de novos materiais, o design vem ganhando progressivamente uma maior liberdade na concepção formal dos produtos industrializados (BONSIEPE, 1986). Toda esta tecnologia favorece a criação de produtos e ambientes que contemplem a real necessidade de usuários, cumprindo os quesitos do Design Universal, que tem como objetivo definir projetos que abarquem toda a diversidade humana (CAMBIAGHI, 2007).

É neste contexto que o presente artigo objetiva apresentar um modelo de balanço acessível, projetado à luz dos conceitos do Design Universal, para um parque infantil da Associação de Pais e Amigos dos Excepcionais - APAE, de uma pequena cidade no interior paulista, mais precisamente destinado às crianças de quatro a 12 com deficiências motoras, intelectuais e múltiplas. $16^{\circ}$ Ergodesign - Congresso Internacional de Ergonomia e Usabilidade de Interfaces Humano Tecnológica: Produto, Informações Ambientes Construídos e Transporte

$16^{\circ}$ USIHC - Congresso Internacional de Ergonomia e Usabilidade de Interfaces Humano Computador

CINAHPA | 2017 - Congresso Internacional de Ambientes Hipermídia para Aprendizagem.

\section{Revisão de literatura}

Nesta seção serão explanados conteúdos relevantes à projetação de um modelo de balanço acessível. Dentre eles, a importância do brincar, conceitos sobre acessibilidade, deficiências e Design Universal, assim como as leis que regem a concepção de produtos acessíveis de parques infantis.

\subsection{A importância do Lazer e do Brincar}

A literatura comumente relaciona o conceito de lazer com o estado de prazer. Gaelzer (1979, p.54) define o lazer como a "harmonia individual entre a atitude, o desenvolvimento integral e a disponibilidade de si mesmo. É um estado mental ativo associado a uma situação de liberdade, de habilidade e de prazer." Para a criança, o lazer é sinônimo de "brincadeira", sendo talvez a atividade mais prazerosa por não implicar obrigações.

A brincadeira é categorizada como uma prática universal (GUSSO; SCHUARTZ, 2005), uma atividade intrínseca ao ser humano que desperta sensações de felicidade, alegria, liberdade e contentamento (LAUFER, 2001). Com o brincar o homem desenvolve potencialidades e trabalha com suas limitações (GUSSO; SCHUARTZ, 2005); estas potencialidades estão ligadas ao desenvolvimento psicomotor e cognitivo, na aquisição e manipulação das regras préestabelecidas (LIMA, 1989). A brincadeira, bem como o lazer, proporciona satisfação pessoal, bem estar, recuperação física e psíquica e, quando praticada em coletividade, torna-se um importante agente de integração social (LAUFER, 2001).

Além das funções recreativas, a brincadeira agrega funções educativas, integrativas, culturais e proporciona ao brincante experiência que transcende as situações banais do cotidiano (GUSSO; SCHUARTZ, 2005). Na brincadeira, a criança pode voar, viver embaixo da água ou ser o rei de um grande reino. Para Laufer (2001), brincar é a manifestação da fantasia e imaginação no mundo real.
Realização:

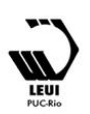




\section{$16^{\circ}$ \\ ERGODESIGN USIHC CINAHPA}

A atividade lúdica para crianças, em contexto amplo, favorece a maturação do sistema motor, desenvolve a coordenação motora, resistência física e se praticadas em ambientes abertos, ao ar livre, proporciona o bem estar geral no organismo do brincante (MEDEIROS, 1975). Porém, são necessários ambientes propícios para as atividades lúdicas ao ar livre, ambientes livres de riscos de acidentes, bem como acolhedores para todos os biótipos de crianças (LAUFER, 2001).

\subsection{Conceitos de Acessibilidade, Deficiências e Design Universal}

O termo acessibilidade pode ser definido como a possibilidade e a condição de alcance, percepção e entendimento para utilização de edificações, espaços, mobiliários, equipamentos urbanos e elementos, com segurança e autonomia (NBR $9050,2004)$ para todas as pessoas, incluindo indivíduos com necessidades especiais ou restrições. A Lei $\mathrm{n}^{\circ} 10.098$ (19 de dezembro 2000) estabelece normas e critérios para a promoção da acessibilidade em ambientes urbanos e privados.

A parcela da população com necessidades especiais é composta por pessoas com restrições temporárias ou portadores de deficiências. As pessoas com restrições temporárias são aquelas que sofreram algum acidente ou fatalidade, resultando em fraturas ósseas, lesões musculoesqueléticas, podendo restringir suas capacidades motoras, sensoriais ou intelectuais por um período de tempo. Existem grupos de pessoas que fazem parte desta categoria sem ter sofrido algum tipo de traumas ou danos. É o caso de gestantes com mobilidade reduzida devido as mudanças físicas e fisiologias, pessoas obesas que podem sofrer limitações motoras, idosos, crianças (com suas pequenas estaturas, ou ainda falta de desenvolvimento intelectual pleno) (BRASIL, 2005).

A deficiência é entendida como prejuízo ou anormalidade permanente, de uma estrutura ou função psicológica, fisiológica, musculoesquelética ou anatômica, gerando desempenho deficitário para atividades cotidianas. As deficiências podem ser subdivididas em cinco categorias: deficiência física, mental, sensorial, orgânica e múltipla. A deficiência sensorial pode ser subdividida em $16^{\circ}$ Ergodesign - Congresso Internacional de Ergonomia e Usabilidade de Interfaces Humano Tecnológica: Produto, Informações Ambientes Construídos e Transporte

$16^{\circ}$ USIHC - Congresso Internacional de Ergonomia e Usabilidade de Interfaces Humano Computador

CINAHPA | 2017 - Congresso Internacional de Ambientes Hipermídia para Aprendizagem. visual e auditiva e quando há a presença de dois ou mais tipos de deficiências associadas, é considerada deficiência múltipla. Cada deficiência pode gerar tipos específicos de inabilidades que resultam em desvantagens para as pessoas que as têm. (BRASIL, 2005; EMMEL, 2010). De acordo com os princípios do Design Universal descritos na Tabela 1 por Staut (2014, p.28), o principal objetivo do Design Universal é minimizar as "desvantagens" decorrentes das deficiências, lançando mão de dispositivos, artefatos e equipamentos que auxiliem e melhorem a qualidade de vida não só de pessoas com necessidades especiais, mas também de qualquer tipo de pessoas.

Entende-se Design Universal como "intervenção sobre espaços, produtos e serviços com a finalidade de permitir a todos o acesso com igualdade de condições, independente de idade, gênero, capacidade e nível cultural" (FRANCISCO; MENEZES, 2011, p.25). Para se projetar produtos, ambientes ou sistemas que estejam pareados aos quesitos de acessibilidade e Design Universal, o projetista deve primeiramente atentar-se às reais demandas de seus usuários, seja este com necessidades especiais, algum tipo de restrição, ou um usuário sem nenhuma especificidade; o produto final deve atender às demandas de todos os usuários de igual ou similar forma (Figura 1).

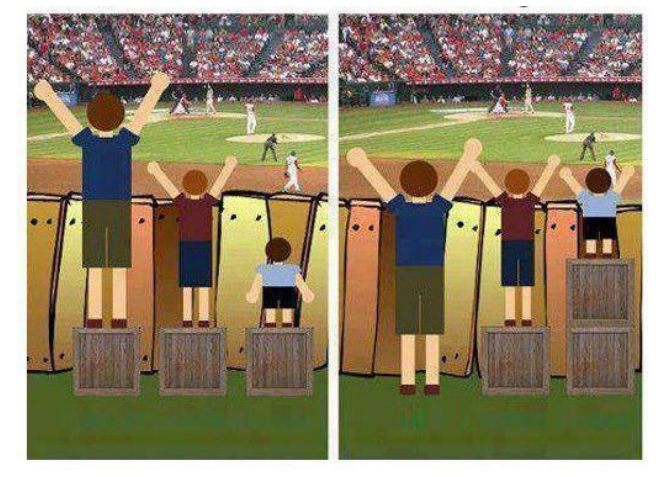

Figura1. Design Universal. Fonte. CAMBIAGHI, 2007.

O Design Universal não é a construção de projetos destinados somente ao público com necessidades especiais ou restrições, trata-se da construção de ambientes, produtos ou criação de tecnologias 


\section{$16^{\circ}$ \\ ERGODESIGN USIHC CINAHPA}

desenvolvidas para todas as pessoas, permitindo a usabilidade em diversas plataformas com segurança e autonomia (CAMBIAGHI, 2007).

Os princípios que regem o Design Universal foram desenvolvidos no período de 1994 a 1997 por profissionais integrantes do projeto Studies to Further Development of Universal Design. Este grupo foi composto por arquitetos, designers de produtos, engenheiros e pesquisadores do desenho ambiental (STAUT, 2014), resultando em sete princípios, demostrados na Tabela 1.

Tabela 1. Princípios do Design Universal

\begin{tabular}{|c|c|}
\hline PRINCÍPIOS & DEFINIÇÃO \\
\hline $\begin{array}{l}\text { Princípio 1: } \\
\text { Uso } \\
\text { equitativo }\end{array}$ & $\begin{array}{l}\text { O projeto deve ter um design que } \\
\text { permita a igual usabilidade de } \\
\text { indivíduos com diferentes } \\
\text { habilidades. }\end{array}$ \\
\hline $\begin{array}{l}\text { Princípio 2: } \\
\text { Flexibilidade } \\
\text { de uso }\end{array}$ & $\begin{array}{l}\text { O projeto deve englobar uma ampla } \\
\text { variedade de preferências e } \\
\text { habilidades individuais. }\end{array}$ \\
\hline $\begin{array}{l}\text { Princípio 3: } \\
\text { Uso simples e } \\
\text { intuitivo }\end{array}$ & $\begin{array}{l}\text { O projeto deve ser de fácil } \\
\text { usabilidade, não dependendo da } \\
\text { experiência, conhecimentos, } \\
\text { proficiência de linguística ou nível } \\
\text { de concentração dos usuários. }\end{array}$ \\
\hline $\begin{array}{l}\text { Princípio 4: } \\
\text { Informação } \\
\text { perceptível }\end{array}$ & $\begin{array}{l}\text { O projeto deve comunicar a } \\
\text { informação necessária ao usuário de } \\
\text { maneira eficaz, independentemente } \\
\text { das condições ambientais ou de } \\
\text { suas habilidades sensoriais. }\end{array}$ \\
\hline $\begin{array}{l}\text { Princípio 5: } \\
\text { Tolerância ao } \\
\text { erro }\end{array}$ & $\begin{array}{l}\text { O projeto deve minimizar os riscos } \\
\text { e as consequências adversas de } \\
\text { ações acidentais ou não } \\
\text { intencionais. }\end{array}$ \\
\hline $\begin{array}{l}\text { Princípio 6: } \\
\text { Baixo esforço } \\
\text { físico }\end{array}$ & $\begin{array}{l}\text { O projeto deve ser utilizado de } \\
\text { forma eficiente, confortável, } \\
\text { demandando o mínimo de fadiga. }\end{array}$ \\
\hline $\begin{array}{l}\text { Princípio 7: } \\
\text { Tamanho e } \\
\text { espaço para } \\
\text { aproximação } \\
\text { e uso }\end{array}$ & $\begin{array}{l}\text { Oferecer ao usuário tamanhos e } \\
\text { espaços adequados para sua } \\
\text { aproximação, alcance, manipulação } \\
\text { e uso. }\end{array}$ \\
\hline
\end{tabular}

Fonte. Adaptado de STAUT (2014, p.28).

O modelo de balanço acessível para o parque da APAE em questão procurou abarcar os princípios supracitados do Design Universal, juntamente com conceitos de acessibilidade, para garantir o uso $16^{\circ}$ Ergodesign - Congresso Internacional de Ergonomia e Usabilidade de Interfaces Humano Tecnológica: Produto, Informações Ambientes Construídos e Transporte

$16^{\circ}$ USIHC - Congresso Internacional de Ergonomia e Usabilidade de Interfaces Humano Computador

CINAHPA | 2017 - Congresso Internacional de Ambientes Hipermídia para Aprendizagem. equitativo, simples e intuitivo a todas as crianças, com necessidades especiais, ou não.

\subsection{Histórico de Parques Infantis}

O conceito de parques para recreação infantil é historicamente recente. Surgiu nos Estados Unidos, na segunda metade do século XIX (TEIXEIRA; FIGUEIREDO, 1970); anteriormente, as crianças dispunham somente de quintais e ruas para brincarem. O movimento pela criação de áreas abertas voltadas à recreação infantil começou em Boston por volta da década de 1880. Entendia-se que as cidades deveriam planejar espaços abertos para recreação, já que o crescimento dos espaços urbanos era exacerbado. Até então, escolas não tinham espaços abertos de recreação infantil.

No fim do século XIX, áreas abertas equipadas com pistas de corrida e espaço para jogos se espalhou em Boston e, na virada do século, a cidade tinha cerca de vinte e uma áreas abertas dedicadas especialmente para pequenas crianças. Estes parques infantis ou playgrounds se estenderam por todos os Estados Unidos e Canadá em anos posteriores (MORI, 2009). Por volta de 1885, uma médica Norte Americana chamada Zakrewska incentivou a incorporação de brinquedos aos playgrounds da época; ela se baseou no modelo de parque infantil criado pelo alemão Emil Hartwight. No Brasil, a criação de parques infantis iniciou-se em 1927 no Rio Grande do Sul, idealizados pelo Professor Frederico Guilherme Gaelzer; nestes os brinquedos e aparelhos de recreação eram improvisados com pneus velhos empilhados, presos e amarrados em árvores (MORI, 2009).

\subsection{Parques Acessíveis}

No princípio VII da Declaração Universal dos Direitos da Criança (1959), é conferido que toda criança tem o direito de desfrutar plenamente de jogos e brincadeiras com finalidades educativas e lúdicas. No artigo 16 do Estatuto da Criança e do Adolescente (lei $\mathrm{N}^{\circ} 8.0699$, de 13 de julho de 1990), é incluído o brincar como um dos aspectos que compreende o direito à liberdade, juntamente com as práticas de esportes e divertimentos em
Realização:

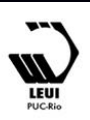




\section{$16^{\circ}$ \\ ERGODESIGN USIHC CINAHPA}

geral (GOMES, 2011). Diante disto, toda criança carece satisfazer suas necessidades de ordem emocional, social, física e intelectual, sendo similares às necessidades para crianças com algum tipo de restrição, com necessidades especiais ou aquelas que não apresentam nenhum tipo de restrição (LAUFER; PAZMINO, 2016).

De acordo com a Declaração Universal dos Direitos das Crianças e do Estatuto da Criança e do Adolescente, é imprescindível a elaboração de parques infantis acessíveis que permitam a integração de crianças, minimizando as diferenças.

Um estudo feito pelo Instituto Brasileiro de Defesa do Consumidor IDEC (1995) em parques infantis pelo Brasil, averiguou que, de forma geral os parques infantis brasileiros não atendem aos critérios básicos de segurança, conforto e manutenção, sendo raros os brinquedos adaptados para crianças com necessidades especiais. Observou carência de dispositivos de segurança, trazendo riscos aos usuários. Tais observações instigaram uma comissão coordenada pela Associação Brasileira de Normas Técnicas (ABNT) e a Associação Brasileira dos Fabricantes de Brinquedos (Abrinq) a organizarem um documento baseado nas normas vigentes na Europa. Em 1999 este documento transformou-se nas normas: NBR 14350(1999), indicando aos fabricantes os cuidados a serem observados na produção dos equipamentos dos parques infantis ou playgrounds (LAUFER, 2001). Em 2012 a norma NBR 14350(1999) foi atualizada gerando a NBR 16071 (2012). Dentre as atualizações, houve uma preocupação em adaptar alguns quesitos da NBR 14350(1999) à realidade Brasileira, como os aspectos climáticos, por exemplo. Nesta foram inclusos alguns quesitos sobre acessibilidade. A norma NBR 16071-1(2012) define os termos de utilização dos playgrounds e a NBR 16071-2 (2012) define os termos de segurança.

\subsection{Brinquedos Acessíveis}

A maioria dos brinquedos de parques infantis não possui design acessível que permita o uso de crianças com necessidades especiais ou restrições, de forma independente. (MATOS, 2007). A $16^{\circ}$ Ergodesign - Congresso Internacional de Ergonomia e Usabilidade de Interfaces Humano Tecnológica: Produto, Informações Ambientes Construídos e Transporte

$16^{\circ}$ USIHC - Congresso Internacional de Ergonomia e Usabilidade de Interfaces Humano Computador

CINAHPA | 2017 - Congresso Internacional de Ambientes Hipermídia para Aprendizagem. construção de brinquedos para parques infantis requer cuidados, devendo oferecer uma mesma usabilidade a todas as crianças, independente das condições físicas ou mentais destas.

Outro quesito importante é a segurança; o brinquedo deve oferecer o máximo de segurança às crianças usuárias (NBR9060, 2004; NBR 16071,

2012) e, para isso, existem leis que norteiam a construção e instalação destes produtos. Os brinquedos de parques infantis devem, necessariamente, acatar as normas de segurança nacional, devendo estar em boas condições de uso, passar por manutenções periódicas, estar muito bem fixados em solos arenosos ou grama e nunca em solos calçados com cimento. Os materiais cortantes como parafusos, porcas, pinos ou outros, que possam estar salientes nos brinquedos, devem ter acabamentos de proteção, de preferência arredondados, para que cantos afiados, agudos ou protuberâncias, não sejam encontrados nos brinquedos (NBR14350, 1999; NBR 16071, 2012).

Entre os brinquedos, rotas acessíveis devem ser construídas com espaços que permitam a transferência de usuários cadeirantes ao brinquedo. As superfícies dos equipamentos recreativos devem ser lisas, sem quinas vivas, sem rebarbas ou protuberâncias, não podendo haver pontos cortantes ou pontos de esmagamento nas regiões móveis ou fixas, devendo ser construídos sem aberturas, com riscos de aprisionamento de cabeça, pescoço, corpo, membros superiores e/ou inferiores, pés ou dedos dos usuários. Para as correntes, correias, ou molas, faz-se necessário capas de proteção, tornando-as inacessíveis às criança (MULLER; ALMEIDA; TEIXEIRA, 2014).

\subsection{O Balanço Acessível}

A lei NBR16071: 2 (2012) traz algumas recomendações para a elaboração de balanços acessíveis:

Os balanços posicionados lado a lado, devem ter distanciamento mínimo de $30 \mathrm{~cm}$ ente os acentos, na posição de repouso, para impedir colisões. $\mathrm{O}$ solo abaixo dos balanços deve atenuar o impacto
Realização:

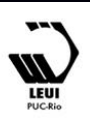




\section{$16^{\circ}$ \\ ERGODESIGN USIHC CINAHPA}

de queda livre; os balanços, tipo cadeiras, devem ter um dispositivo para evitar que os usuários deslizem pela estrutura do acento; os balanços confeccionados com pneus não podem acumular água; os componentes do sistema de suspensão dos balanços não podem apresentar rupturas, deformações permanentes ou danos; os balanços devem ter encostos. Devem guardar uma distância mínima do solo, em posição de repouso, de $35 \mathrm{~cm}$ e se caso sejam confeccionados por pneus, essa distância diminui para $30 \mathrm{~cm}$.

Alguns pesquisadores afirmam que as leis de acessibilidade para parques infantis NBR 9050(2004) e a NBR 16071(2016) são insuficientes, não abarcando as necessidades de pessoas com deficiência ou restrições. Em 2001, Laufer pesquisou adaptações de brinquedos de parques infantis às crianças com paralisia cerebral em Curitiba-PR. Neste estudo a pesquisadora teceu uma série de recomendações para a construção de brinquedos acessíveis e também projetou modelos de brinquedos, dentre eles um balanço, apresentado na Figura 1. Mais recentemente em 2013, Muller realizou uma pesquisa em parques infantis existentes em escolas do ensino regular do município de Novo Hamburgo RS, tendo como foco o usuário cadeirante. A pesquisadora também teceu recomendações inerentes aos brinquedos acessíveis. Algumas dessas recomendações referem-se à elaboração de propostas para adaptação de trajeto entre os brinquedos, outras referem-se ao projeto de brinquedos acessíveis, com Design Universal.

Baseadas nestes dois estudos há algumas recomendações utilizadas no modelo de balanço a ser apresentado no presente artigo. Segundo Laufer (2001) e Muller (2013), os balanços devem ter encostos nos assentos a fim de evitar a projeção para traz dos usuários; deve-se ter cinto de segurança para manter os usuários seguros e eretos nos acentos, inibindo a flexão de tronco; proteções laterais com formas arredondadas, a fim de proporcionar segurança e conforto, principalmente para os usuários sem controle de tronco; descansos para braços; também são necessárias pegas ergonômicas para os usuários se segurarem, caso consigam. Outro dispositivo importante para $16^{\circ}$ Ergodesign - Congresso Internacional de Ergonomia e Usabilidade de Interfaces Humano Tecnológica: Produto, Informações Ambientes Construídos e Transporte

$16^{\circ}$ USIHC - Congresso Internacional de Ergonomia e Usabilidade de Interfaces Humano Computador

CINAHPA | 2017 - Congresso Internacional de Ambientes Hipermídia para Aprendizagem. beneficiar a postura dos usuários é o chamado freio, colocado na parte central anterior do assento ficando entre os membros inferiores dos usuários, evitando o deslocamento do corpo para frente, conforme ilustrado na Figura 2.

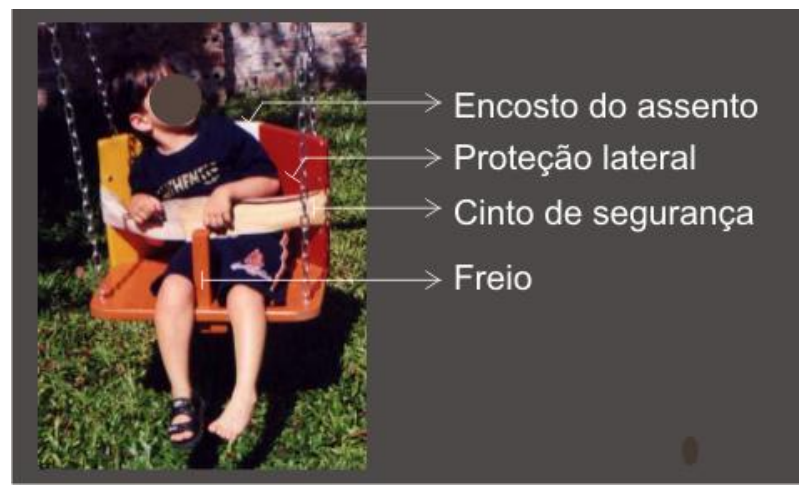

Figura 2. Exemplo de balanço acessível. Fonte. Laufer (2001).

\section{Material e Método}

Este trabalho é de caráter qualitativo, sendo utilizados dois métodos científicos de investigação: visita exploratória in locu e entrevistas semi-estruturadas. As entrevistas foram realizadas com profissionais de uma APAE, situada em uma pequena cidade no interior paulista.

\subsection{Metodologia}

O modelo do balanço projetado para o parque da APAE foi estruturado com base na metodologia de Munari (1998). Esta metodologia se justifica por meio de uma real necessidade (problema); neste estudo, a necessidade foi detectada através da visita exploratório e entrevistas com funcionárias da instituição pesquisada.

O problema projetual foi: criar um modelo de balanço acessível lançando mão dos princípios do Design Universal, sendo confortável, ergonômico, resistente e formalmente atrativo aos usuários com necessidades especiais, contemplando a faixa etária de quatro a 12 anos. O balanço deveria ser capaz de acondicionar os usuários de forma confortável e segura, a fim de evitar acidentes; ser durável, resistente às intempéries do ambiente (chuva, calor e sol). Devendo ser de fácil higienização e de custo 


\section{$16^{\circ}$ \\ ERGODESIGN USIHC CINAHPA}

$16^{\circ}$ Ergodesign - Congresso Internacional de Ergonomia e Usabilidade de Interfaces Humano Tecnológica: Produto, Informações Ambientes Construídos e Transporte

$16^{\circ}$ USIHC - Congresso Internacional de Ergonomia e Usabilidade de Interfaces Humano Computador

CINAHPA | 2017 - Congresso Internacional de Ambientes Hipermídia para Aprendizagem. não elevado.

\subsection{Coleta de dados}

Foi elaborado um roteiro de entrevista semiestruturada, destinada à coordenadora e a uma professora da instituição, contendo 3 temas:

a) Instituição: questões sobre o histórico da instituição, missão, objetivos, quantidades de alunos, tipo de patologias, necessidades e restrições dos alunos.

b) Parque Infantil: questões sobre quem são os usuários do parque, quantidade, faixa etária e tipos de necessidades.

c) Balanço: foi perguntado quais as dificuldades as crianças encontravam para acessá-los. Como as professoras lidavam com estas dificuldades e sugestões para um balanço ideal.

\section{Resultados}

\subsection{Resultados da entrevista Semi-estruturada}

\section{a)Caracterização da instituicão}

A instituição pesquisada foi a APAE situada em uma pequena cidade no interior paulista. Fundada em 1972, possui caráter assistencial, sem fins lucrativos. Esta instituição está voltada para educação e para o atendimento especializado às pessoas com deficiência intelectual, deficiência múltipla e síndromes. Desenvolve projetos e programas que visam melhorar as condições de desenvolvimento humano e social. A instituição atende indivíduos do inicio ao fim da vida e possui em torno de 320 pacientes.

\section{b) O parque infantil e seus usuários}

O Parque infantil, presente na instituição, foi criado posteriormente a sua fundação e recebe por volta de 80 usuários de zero a 12 anos, com deficiências múltiplas, porém predominam as deficiências motoras e intelectuais. As patologias e síndromes mais comuns nos usuários são: Paralisia Cerebral, Síndrome de Down, Transtorno do Espectro Autista e Hidrocefalia.

O parque, bem como os brinquedos, não atende aos critérios de segurança e acessibilidade, regidos pela NBR 9050(2004) e NBR 16071(2-12), (figura 3. A, B e C). Possui uma rampa de acesso para cadeirantes, porém não é continuada por passarelas calçadas (Figura 3. C), o solo é de terra batida, os brinquedos são todos de madeira com conservação precária, não possuindo requisitos de segurança e acessibilidade.

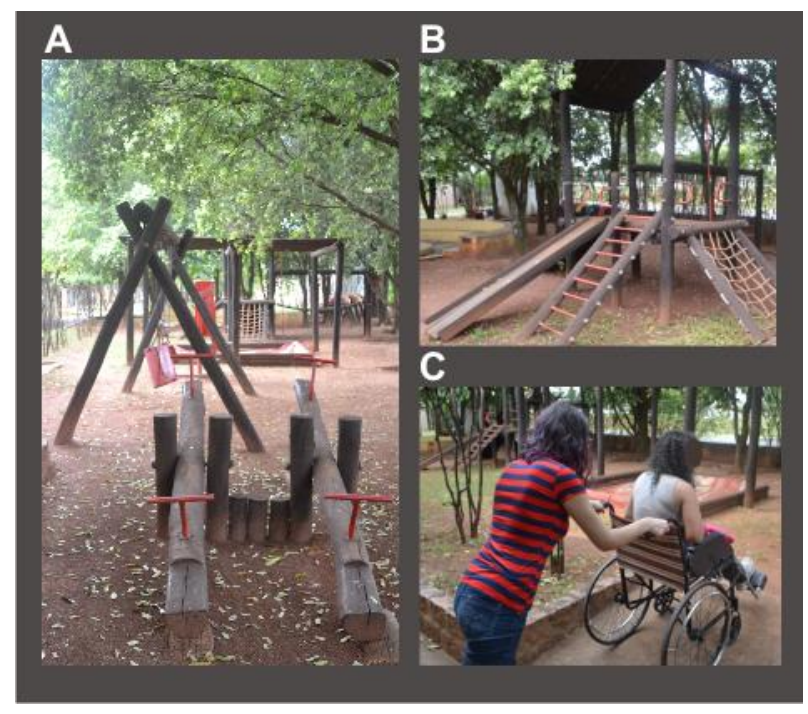

Figura 3. Imagens do parque da APAE em cidade do interior paulista (A, B e C). Fonte. Produzida pelos autores.

\section{c) $\underline{\text { O balanço }}$}

Os balanços da instituição são inadequados, de acordo com a norma NBR 16071(2012), as recomendações de Laufer (2001) e Muller (2013) (Figura 4). Não possuem encostos nos assentos, cinto de segurança, proteção lateral, descanso para braços, pega ergonômica, nem freio; além disso, é feito de madeira, podendo lascar ou até quebrar. Os balanços ficam presos a um cadeado para evitar o acesso das crianças sem a presença dos professores.
Realização:
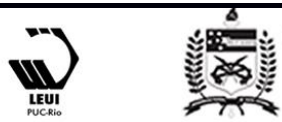


\section{$16^{\circ}$ \\ ERGODESIGN USIHC CINAHPA}

Para a criança com mobilidade reduzida (que não possui controle de tronco e/ou membros superiores ou inferiores) poder utilizar o balanço, a professora precisa sentar-se no balanço colocando a criança em seu colo, abraçando-a. Este gesto, além de ser desconfortável e desgastante fisicamente para a professora, pode gerar à criança uma percepção de maior dependência e incapacidade.

Em relação às sugestões colhidas na entrevista com as funcionárias para a construção do balanço, o item mais ressaltado foi o cinto de segurança, seguido do encosto para o acento e um formato de cadeira em que a criança, mesmo sem controle de tronco, pudesse assentar-se sozinha, enfatizando sua independência.

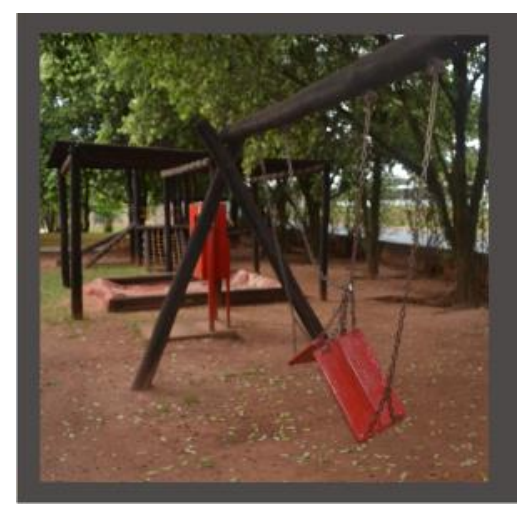

Figura 4. Imagens dos balanços do parque da APAE em cidade do interior paulista. Fonte. Produzida pelos autores.

\subsection{Modelo de Balanço Acessível}

O Modelo de balanço projetado procurou acatar as sugestões das funcionárias da instituição pesquisada, acatar os princípios de Design Universal, atender as especificações das normas NBR 9050(2004), NBR16071(2012), bem como as recomendações de Laufer (2001) e Muller (2013) sobre brinquedos acessíveis em parques infantis, para usuários com necessidades especiais.

O balanço possui encostos nos assentos; cinto de segurança, proteção lateral, descanso para braços, pega ergonômica e freio, elementos indicados na Figura 5. $16^{\circ}$ Ergodesign - Congresso Internacional de Ergonomia e Usabilidade de Interfaces Humano Tecnológica: Produto, Informações Ambientes Construídos e Transporte

$16^{\circ}$ USIHC - Congresso Internacional de Ergonomia e Usabilidade de Interfaces Humano Computador

CINAHPA | 2017 - Congresso Internacional de Ambientes Hipermídia para Aprendizagem.
As dimensões do balanço, com largura interna de $42 \mathrm{~cm}$ e altura de $61 \mathrm{~cm}$, permitem o acesso de diferentes biótipos de usuários, como crianças obesas e demasiadamente grandes. É importante ressaltar que crianças com síndrome de Down possuem alta probabilidade ao sobrepeso, devido à disfunção lipídica desencadeada pela síndrome (MARTIN, 2011).

O material recomendado para o balanço foi o polipropileno. Trata-se de um termoplástico de fácil moldagem e coloração, alta resistência à fratura por flexão ou fadiga; boa resistência ao impacto, boa estabilidade térmica, atóxico, com baixa absorção de umidade e de baixo custo. (CANEVAROLO 2002).

O modelo em questão ainda não recebeu um protótipo para testes de usabilidade, porém por contemplar quesitos importantes de segurança e acessibilidade, acredita-se ser uma boa alternativa de balanços para parques infantis de forma geral, garantindo a equidade e facilidade no uso por todas as crianças.

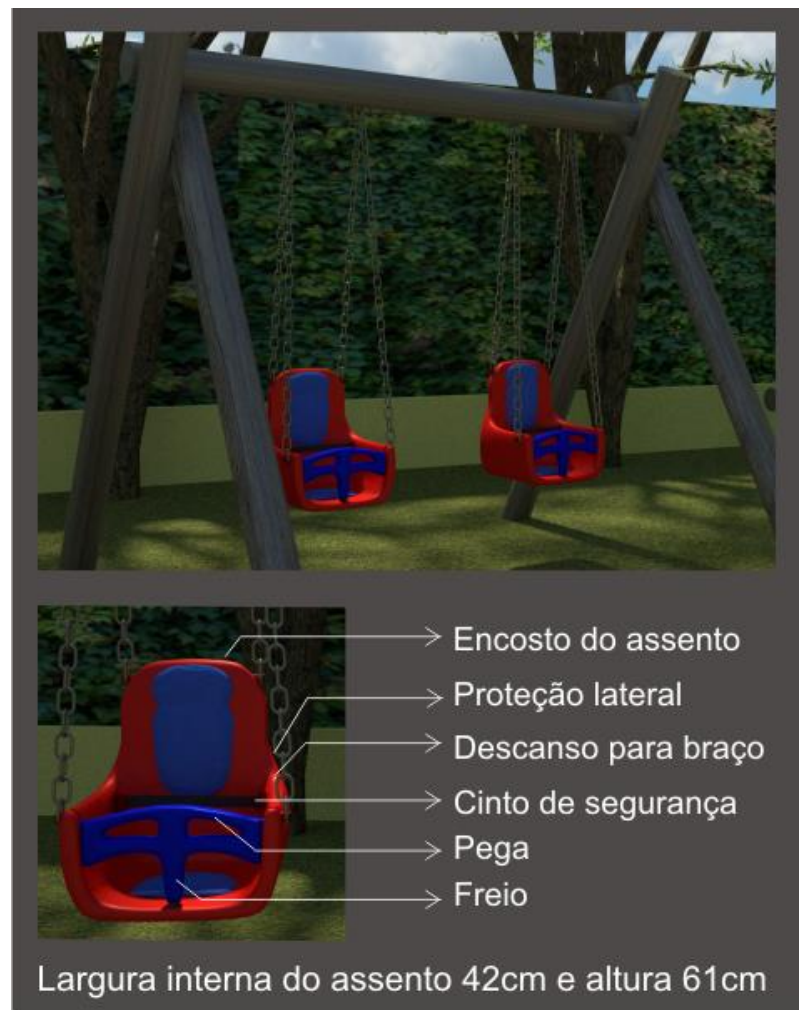

Figura 5. Modelo de Balanço Acessível. Fonte. Fernandes, 2016.
Realização:

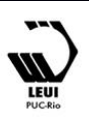


$16^{\circ}$ Ergodesign - Congresso Internacional de Ergonomia e Usabilidade de Interfaces Humano Tecnológica: Produto, Informações Ambientes Construídos e Transporte

$16^{\circ}$ USIHC - Congresso Internacional de Ergonomia e Usabilidade de Interfaces Humano Computador

CINAHPA | 2017 - Congresso Internacional de Ambientes Hipermídia para Aprendizagem.

\section{Considerações Finais}

O presente artigo buscou apresentar um modelo de balanço acessível baseado nos princípios do Design Universal para crianças com necessidades especiais, mais especificamente projetado para o parque de uma APAE, situada em uma pequena cidade no interior paulista. Buscou também elencar as leis de acessibilidade e segurança de brinquedos, bem como as recomendações de pesquisadores sobre a construção de brinquedos acessíveis.

Os brinquedos de parques infantis acessíveis são em sua maioria encontrados em instituições de apoio às pessoas com deficiências (CORRÊA; MANZINI, 2007). A preocupação com a acessibilidade e o Design Universal de brinquedos de parques infantis, deveria se estender a todas as esferas da sociedade, para parques municipais e em escolas públicas ou privadas, não se restringindo apenas em instituições específicas para pessoas com necessidades especiais. O presente estudo identificou que nem mesmo instituições especializadas possuem brinquedos adequados ou acessíveis no ambiente de seus parques infantis, haja visto o exemplo do parque da APAE em questão (Figura 3). Por outro lado, é sabido que o custo para se adequar parques infantis, segundo as normas e leis brasileiras que regem a acessibilidade, ainda são elevados. Neste contexto, são necessários mais estudos sobre as temáticas de parques infantis acessíveis, não só voltados à projetação de brinquedos adaptados, mas também à investigação destinada a novos materiais e maneiras menos custosas de se implantar a acessibilidade nestes locais, contribuindo para que um número maior de crianças possam usufruir do direito ao lazer e de brincar.

\section{BIBLIOGRAFIA}

ABNT (Associação Brasileira de Normas Técnicas). NBR 14350-1: Segurança de brinquedos de playground. Parte 1: Requisitos e métodos de ensaio. Rio de Janeiro: ABNT, 1999b.
ABNT (Associação Brasileira de Normas Técnicas). NBR 9050 - Acessibilidade a Edificações, Mobiliário, Espaços e Equipamentos Urbanos. (Esta Errata 1 de 30.12.2005 corrige a ABNT NBR 9050:2004) Rio de Janeiro: ABNT, 2005.

ABNT (Associação Brasileira de Normas Técnicas). NBR 16071-1:2012, Playgrounds. Parte 1: Terminologia, que define os termos utilizados para playgrounds.

ABNT (Associação Brasileira de Normas Técnicas). NBR 16071-2:2012, Playgrounds. Parte 2: Requisitos de segurança, que especifica os requisitos de segurança para os equipamentos de playground destinados a reduzir os riscos que os usuários não sejam capazes de prever ou que possam ser razoavelmente antecipados.

BRASIL. Coordenadoria Nacional para Integração da Pessoa Portadora de Deficiência; Acessibilidade - Brasília; Secretaria Especial dos Direitos Humanos, 2005.

BONSIEPE, Gui et. al. Metodologia

Experimental: Desenho Industrial. Brasília: CNPq/Coordenação Editorial, 1986.

CAMBIAGHI, Silvana Serafino. Desenho Universal: métodos e técnicas para arquitetos e urbanistas. São Paulo: Editora Senac, São Paulo, 2007.

CANEVAROLO JR., Sebastião V. Ciência dos polímeros: Um texto Básico para Tecnólogos e engenheiros.2ed. São Paulo: Artliber Editora, 2002

CORRÊA M,P; MANZINI J,E. Acessibilidade em Parque Infantil: Um Estudo em Escolas de Educação Infantil. Congresso de Iniciação Científica da Unesp (2007). Disponível em < http://33reuniao.anped.org.br/33encontro/app/webr oot/files/file/Trabalhos\%20em\%20PDF/GT076088--Int.pdf> acesso em 10 jan. 2017.

Declaração Universal dos Direitos das Crianças UNICEF. Assembleia Geral 1386 (XIV), de 20 de Novembro de 1959. 
$16^{\circ}$ Ergodesign - Congresso Internacional de Ergonomia e Usabilidade de Interfaces Humano Tecnológica: Produto, Informações Ambientes Construídos e Transporte

$16^{\circ}$ USIHC - Congresso Internacional de Ergonomia e Usabilidade de Interfaces Humano Computador

CINAHPA | 2017 - Congresso Internacional de Ambientes Hipermídia para Aprendizagem.
EMMEL Maria Luísa Guillaumon; GOMES Gabriela BAUAB; Juliana Pedroso. Universidade com Acessibilidade: Eliminando Barreiras e Promovendo a Inclusão em uma Universidade Pública Brasileira. Revista Brasileira de Ciências da Saúde, Volume 14 Número 1 Páginas 7-20, 2010. ISSN 1415-2177.

Estatuto da Criança e do Adolescente: Lei $\mathbf{N}^{\mathbf{0}}$ 8.069, de 13 de Julho de 1990. Disponível em < http://www.planalto.gov.br/ccivil_03/leis/L8069.ht $\underline{\text { m}}>$ acesso em 15 jan, 2017.

FRANCISCO P, C, M; MENEZES A, M. Design Universal: Acessibilidade e espaço construído. Construindo, Belo Horizonte, v.3, n.1, p.25-29, 2011. Disponívem em < http://fumec.br/revistas/construindo/article/view/17 63/1129> acesso em 10 jan. 2017.

FERNANDES, Eduardo Augusto Souza. Balanço Acessível. Projeto de disciplina de graduação do curso de Design Gráfico. Centro Universitário UNIFAFIBE, Bebedouro, 2016.

GAELZER, Lenea. Lazer: bênção ou maldição? Rio Grande do Sul: Sulina,1979.

GOMES, Ivete de Araújo. A importância e influencia do Lúdico sobre o desenvolvimentos de alunos com paralisia cerebral. (2011), f 47. Monografia ( Programa de Pós graduação em Processos de desenvolvimento Humano e saúde). Departamento de psicologia escolar e do desenvolvimento - PED. Universidade de Brasília -UNB. Brasilia, 2011.

GUSSO, S,F,K; SCHUARTZ, M, A. A Criança e o Lúdico: A Importância Do "Brincar" Sandra de Fátima Krüger PUPR Prof ${ }^{a}$ Ms. Maria Antonia. Anais EDUCERE, 2005.

IDEC - Instituto Brasileiro de Defesa do Consumidor. Revista IDEC, 1995. Disponível em < http://www.idec.org.br/revista/> acesso em 8 jan. 2017.

IBGE, Instituto Brasileiro de Geografia e Estatística. Cartilha do censo 2010: A Deficiência no Brasil, 2012. Disponível em < http://www.pessoacomdeficiencia.gov.br/app/sites/ default/files/publicacoes/cartilha-censo-2010pessoas-com-deficienciareduzido.pdf $>$ acesso em 4 dez. 2016.

\section{LAUFER, Adriana Mariana. Recomendações} para projeto de brinquedos de recreação e lazer existentes em playgrounds adaptados à criança com paralisia cerebral. 2001. 44 f. Dissertação (Mestrado em Engenharia de Produção) Programa de Pós-graduação em Engenharia de Produção Universidade Federal de Santa Catarina, Florianópolis, 2001.

LAUFER, A, M; PAZMINO, A,V. Parâmetros de Projeto para equipamentos lúdicos em espaço Público Baseados nos Princípios do Design Universal. Cadernos da Escola de Comunicação. Unibrasil, vol 4, 2016.

LEI No 10.098. 19 de dezembro 2000, Capítulo I, artigo II, 2000. Disponível em <

http://www.planalto.gov.br/ccivil_03/leis/L10098.h $\underline{\mathrm{tm}}>$ acesso em 10 fev. 2017.

LIMA, Mayumi. A cidade e a criança: São Paulo: Nobel, 1989.

MARTIN, Juan Eduardo Samur-San; MENDES, Roberto Teixeira; HESSEL, Gabriel. Peso, estatura e comprimento em crianças e adolescentes com síndrome de Down: análise comparativa de indicadores antropométricos de obesidade. Rev. Nutr., Campinas, v. 24, n. 3, p. 485-492, jun. 2011. Disponível em

$<$ http://www.scielo.br/scielo.php?script=sci_arttext \&pid=S1415-

52732011000300011\&lng=pt\&nrm=iso $>$. acessos em 16 mar. 2017.

http://dx.doi.org/10.1590/S141552732011000300011.

MATOS, K. Posso brincar com você? Um estudo da possibilidade de crianças cegas brincarem com videntes sob a ótica do Desenho Universal. 2007. 284 f. Dissertação (Mestrado em Desenho Industrial) - Faculdade de Arquitetura Artes e 


\section{$16^{\circ}$ \\ ERGODESIGN USIHC CINAHPA}

Comunicação, Universidade Estadual Paulista, Bauru, 2007.

MEDEIROS, Ethel Bauzer. O lazer no planejamento urbano. $2^{\circ}$ ed. Rio de Janeiro: Fundação Getúlio Vargas, 1975.

MORI, Raquel Biem. Ludicidade: projeto arquitetônico e paisagístico de educação infantil. 2009. . Trabalho de conclusão de curso (bacharelado - Arquitetura e Urbanismo) Universidade Estadual Paulista, Faculdade de Arquitetura, Artes e Comunicação, 2009. Disponível em: <http://hdl.handle.net/11449/120097> acesso em 10 jan, 2017.

MULLER, Marcelle Suzete, ALMEIDA, Eloisa Santa de, TEIXEIRA,Fábio Gonçalves . Design Inclusivo: playground para todas as crianças HFD Human factors in design, v.3, n.5, p 17 27, 2014. Disponível em<http://www.revistas.udesc.br/index.php/hfd/art icle/view/5072> Acesso em 10 jan. 2017.

MUNARI, Bruno. Das coisas nascem as coisas. São Paulo: Martins Fontes, 1998.

STAUT Lucy Ana Vilela. Usabilidade Universal na Arquitetura: Método de Avaliação baseado em heurísticas. F249, 2014. (Dissertação de Mestrado). Programa de Pós Graduação Arquitetura, Tecnologia e Cidade - Faculdade de Engenharia Civil, Arquitetura e Urbanismo da Unicamp, Campinas.

TEIXEIRA, Mauro S; FIGUEIREDO, Jarbas S. de. Recreação para todos: manual teórico e prático. São Paulo: Obelisco, 1970. $16^{\circ}$ Ergodesign - Congresso Internacional de Ergonomia e Usabilidade de Interfaces Humano Tecnológica: Produto, Informações Ambientes Construídos e Transporte

$16^{\circ}$ USIHC - Congresso Internacional de Ergonomia e Usabilidade de Interfaces Humano Computador

CINAHPA | 2017 - Congresso Internacional de Ambientes Hipermídia para Aprendizagem. 